\title{
EJEM \\ Econ.J.Emerg.Mark.

\section{Similarity evidence between the country risk and the idiosyncratic risk: An empirical study of the Brazilian case}

\author{
André Assis de Salles \\ Polytechnic School, Federal University of Rio de Janeiro, Rio de Janeiro, Brazil \\ Corresponding author: aadesalles@gmail.com
}

\begin{tabular}{l} 
Article Info \\
\hline Article bistory: \\
Received : 29 January 2021 \\
Accepted : 8 March 2021 \\
Published : 1 April 2021 \\
JEL Classification Code: \\
C22, C58, E44, F21, F43 \\
Author's email: \\
aadesalles@gmail.com \\
DOI: 10.20885/ejem.vol13.iss1.art6
\end{tabular}

\begin{abstract}
Purpose - This paper estimates the idiosyncratic risk (IDR) time series in the Brazilian economy and verifies its interaction with the Brazilian country risk indicators, measured by the EMBI+ (the Emerging Markets Bond Index).

Methods - This paper estimates various regression models to capture the dynamic nature of the variables. The models include the heteroscedastic conditional autoregressive models and vector error correction models (VECM).
\end{abstract}

Findings - The results show similarities or associations between the two indicators with interactions in the short and long run. The idiosyncratic risk proves to be a relevant indicator of the risk of economic activities implemented within the scope of the Brazilian economy and can help evaluate investments in related projects. This results also provide evidence of cointegration between the EMBI+ and IDR variations.

Implication - This result suggests an alternative way for obtaining estimates of the expected return required by economic agents in financing and investing in productive and infrastructure projects necessary for developing the Brazilian economy that provides greater employability and good social welfare.

Originality - This paper provides an alternative estimate of the time series proxy of idiosyncratic risk in the Brazilian economy. It also compares the results with the time series results obtained from the country risk measure EMBI+, widely used among resource managers in the international markets.

Keywords - Idiosyncratic risk, country risk, causality, cointegration

\section{Introduction}

Knowledge of available indicators is necessary for decision-making in investing and financing the productive projects and the trade-off risk-return for an optimal allocation of resources in an economy. It is essential in, especially, financial resources shortage periods, one frequent situation in many developing economies and, particularly, in the Brazilian economy.

Economic policymakers and managers in emerging economies attempt to attract capital to productive projects that develop their economies by providing greater employment opportunities and social welfare. On the other hand, resource managers seek to invest and finance projects or economic activities that can offer returns that compensate the risk assumed by allocating resources in these economies as well as any investor attempt to obtain the most meaningful information about their investment possibilities among investment options available in the international market. 
Investment and financing of productive projects or the production in economies occur through the financial market, particularly the capital market. The productive projects provide the necessary conditions for the economic development of national economies and to maintain jobs and income growth in the capital market, the source of resources for investment and financing. Therefore, a relevant advanced indicator of an economy is its capital market performance, whose prime indicator is the stock market profitability index that reflects the expectations of economic agents. From these stock market profitability indices, risks associated with productive projects, national economies sectors, a national economy, and the global economy can be estimated. The total risk of asset projects portfolio and its two components, the market risk and the idiosyncratic or specific risk can be estimated through the assets or projects portfolio's returns and the market portfolio returns. The finance theory studies investment and financing through appropriate methodologies to observe the risk associated with productive activities or productive projects. This theory was developed in the last seven decades from the portfolio optimization model, suggested by Markowitz (1952), and the model's determination specifies the risk-return trade-off. Hence, the risk quantification of a diversified portfolio can occur through the market model, presented in the literature by Sharpe (1963) in one of the finance theory seminal works. The market model can be represented by a stochastic model with an asset or an asset portfolio return as a response variable and the market portfolio return as a regressor whose proxy can be obtained in each national economy's stock market profitability indexes.

This way, each national economy provides an indicator representing the market portfolio that encompasses the most productive projects: the indicator closest to a market portfolio of that economy. It can be represented by the stock market profitability index of each of these economies. In contrast, the indicator representing the global market portfolio or the world economy can be obtained by a portfolio that gathers all national markets or a profitability index of that portfolio or the global stock market. Some financial market institutions calculate and make profitability indices for the national stock markets and the global stock market available. This way, one can build market models for each national economy and, in particular, for the Brazilian economy.

The total risk of each economy integrated into the world economy can be estimated as well as their components, the market risk, and the idiosyncratic risk. The market risk reflects the events that affect each national economy, such as wars, climatic disasters, and pandemics. In contrast, the idiosyncratic risk is associated with events that affect only a particular national economy or a country, that is, the risk part that may produce a direct impact motivated by a specific economic measure that affects a national economy. Therefore, the expectations of idiosyncratic risk indicate how each economy is mainly affected by events that concern only a country or how each country manages its productive projects and economic activity inherent problems. Hence, idiosyncratic risk can be recognized as a relevant indicator for investors in general.

Another relevant parameter associated with the risk of economic activity in national economies concerns the sovereign risk premium measured by country risk, whose main indicator is the Emerging Markets Bond Index (EMBI+). This index quantifies the margin that international investors consider a fair return for investing in productive projects or investing in bonds referenced by productive projects developed in a given national economy.

Many types of research have been carried out on the idiosyncratic risk of investment projects, investment project portfolios, or national economies in general. These studies are differentiated by how this risk is estimated, such as the models used and estimation methods, and the relationship or association of the indicators. It happens with the returns or with other indicators of these investment projects or investment project portfolios. The same occurs in researches related to sovereign risk or the premium associated with this risk. Further on, in this work, some of these researches will be commented.

This work aims to estimate the idiosyncratic risk time series of the Brazilian economy and verify its interaction with the EMBI+ Brazil, the Brazilian country risk indicator. It does so using heteroscedastic conditional autoregressive models, autoregressive vector models with error correction, respectively. This paper intends to provide an indicator for the risk associated with the Brazilian economy as an alternative to country risk. 
In addition to this introduction, other sections are presented in this work as follows. Section 2 presents a brief of the research related to the topics discussed here, while Section 3 presents its methodological approach. The sample or data employed that are presented in Section 4. And the analysis of the results obtained is presented in Section 5. Finally, in Section 6 are the conclusion and final comments of the work followed by the bibliographic references.

The stock profitability index is a proxy for a diversified portfolio for each of the economies that make up the global economy, which allows estimating national and global economy volatilities. Asset volatility or total risk of investment projects portfolios or an economy can be divided into two parts. The first one is the market risk, which refers to the risk affecting the portfolio or all economies inserted in the global market. The second one is the idiosyncratic risk, which can be minimized with the diversification of the portfolio and recognized as an inherent risk to each national economy inserted in the global economy. Idiosyncratic risk expectations describe how each economy is particularly affected by events related to only a respective country. Each country manages the problems related to its products and infrastructure projects that can provide wellbeing.

From Sharpe (1963), many types of research have been carried out to determine the total risk and its components. The market model estimation allows for determining the beta coefficient, the primary indicator of market risk, and the idiosyncratic risk also called specific risk. In a pioneering work, Rosenberg and McKibben (1973) search to make equity systematic and specific risk predictions proposing stochastic models construction using the market model concept to determine the beta coefficient and the idiosyncratic. Based on the work of Rosenberg and McKibben (1973)-many types of research were developed to extend and improve the methods employed. Fu (2009) sought to estimate the idiosyncratic risk and its relationship with the monthly stock returns using the three-factor model suggested by Fama and French (1993) and the Autoregressive Conditional Heteroscedasticity (ARCH) models family available in the finance literature, developed from the seminal work by Engle (1982) and the work by Bollerslev (1986). Angelidis and Tessaromatis (2008) observe that idiosyncratic risk has been neglected to the detriment of a more considerable emphasis given to the systematic risk in determining the risk premium, and Campbell, Hilscher, and Szilagyi (2008) emphasize the importance of assessing idiosyncratic risk.

In general, market volatility increases in the periods leading up to crises and during periods of crisis. In the recent period of the world economy and as noted by Kalra (2008) with the North American subprime crisis, which started in the middle of 2007, and the decrease in the global market credit supply: the global economy and in capital markets, in particular, was out of control. Among the most recent studies that attempt to estimate idiosyncratic risk are Chang, Ko, Nakano, and Ghon Rhee (2018), with data from the Japanese economy, Shi and Zhou (2019), with data from the Chinese stock market, and Blitz, Hanauer, and Vidojevic (2020), which treats this risk as an anomaly, can be mentioned. Works related to sanitary crises or epidemics and pandemics that have occupied academic researchers with studies that seek to verify changes in the productive projects, in productive projects portfolios, in economic sectors, and national economies risk, should also be mentioned. Among these researches; Naidenova, Parshakov, and Shakina (2020), which deals with idiosyncratic and systematic shocks caused by the Covid-19 Pandemic in the financial markets, and the recent research by Atkenson (2020), by Barro, Ursua, and Weng (2020), by Anderson, Heesterbeek, Klinkenberg, and Hollingsworth (2020), Mckibbin and Fernando (2020), and Gourinchas (2020), on the influence of the crisis caused by the Covid-19 Pandemic in the macroeconomic environment.

A prominent aspect of emerging economies is the level of accentuated indebtedness, in particular external indebtedness. Since in several periods, there is a scarcity of resources requiring external resources contribution. Hence, from the resource managers' point of view, all available indicators are crucial for efficient allocation of resources in these economies and assisting investment decision making. Among many parameters, investors and asset managers observe two of the most relevant indicators across the risky bond markets: country risk and risk or total risk. Total risk and country risk, which measure the stability of national economies through the ability 
to honor foreign debt payment, is one of the main parameters observed for the efficient allocation of resources in the international market. Emerging markets have proven to be increasingly efficient in terms of information, which should reveal associations between these parameters in the long run. Although the country risk can be represented by the Emerging Markets Bond Index (EMBI+), it does not present any problems regarding its determination since the prices of these securities can be observed directly in the market for these securities.

In contrast, sovereign risk refers to the credit risk of transactions that involve the state and is measured by credit rating or rating agencies such as Moody's, Fitch and Standard \& Poor's. To mention those of more relevance, country risk refers to the excess return required to invest in a particular country, a risk premium, or margin which the EMBI+ indices can observe quotes for each country or by the CDS - Credit Default Swap. Resource managers observe these indicators for resource allocation. When the risk of a given market increases, investors seek to reduce the total risk of their portfolios by reallocating assets, transferring resources from bonds linked to emerging markets to developed markets in a movement called the flight to quality.

Many studies and researches have stimulated academic interest in lines of research that involve sovereign risk and country risk, especially research related to the behavior of the EMBI+ and CDS' indexes in emerging countries. Some studies seek to relate these indices to macroeconomic indicators using various methodologies, especially those that involve statistical inference. The studies that can be mentioned are Kocsis (2013) which uses principal components analysis to decompose market indicators as the EMBI+ and CDS of a representative sample of national economies; Herrera et al. (2013), which links EMBI+ with other systematic risk factors in the Mexican economy; Cristo \& Gómez-Puig (2014) which presents evidence of the relationship between EMBI+ and macroeconomic variables from seven Latin American countries using autoregressive vector models with error correction mechanism and Alfaro, Medel, and Moreno (2017) that studies the country risk behavior and other three variables involving volatility and exchange rate of Latin American countries, through an autoregressive vector model. It should be noted that Alfaro et al. (2017) carry out a particular study for the Chilean economy, including the copper price in the international market, and point out that Alfaro et al. (2017) emphasize that: among Latin American countries, EMBI+ is more relevant to Brazil than to other Latin American countries.

\section{Methods}

In the construction and estimation of stochastic models necessary to achieve this work objectively, it is crucial to verify some assumptions. This way the normality is a fundamental assumption. Thus, the normality hypothesis test suggested by Jarque and Bera as described in Gujarati and Porter (2011) or Wooldridge (2012) was used. Another fundamental assumption for this research refers to stationarity. According to Gujarati and Porter (2011), it must be highlighted that nonstationarity commonly causes spurious regressions even in large samples. The stationarity test used here was the Dickey-Fuller Augmented (ADF). It is crucial to mention that the absence of stationarity can be corrected through differentiation processes. Further details can be seen in Gujarati and Porter (2011). Another fundamental statistical test for doing this work refers to the cointegration hypotheses. According to the description presented in Enders (2010), the Johansen test was selected to use among the cointegration tests available in the literature because of its suitability for estimating the autoregressive vector model shown below. Besides that, other statistical hypotheses tests inherent by the estimated models were performed.

For the conception of this research, the time series of country risk and idiosyncratic risk of the Brazilian economy was initially elaborated. The country risk is represented by its leading indicator EMBI+. It can be observed in the market, while the idiosyncratic risk determination is estimated using the market model, a stochastic linear model that relates the return of an asset to the return of the market portfolio.

The concept and determination of total risk and its components, systematic risk, and idiosyncratic risk, were established based on the Single Index Model, or market model, proposed by Sharpe (1963) that relates the returns of an asset portfolio and market portfolio returns that 
were previously mentioned. Within this scope of work, the risk asset portfolio is characterized by the profitability index of the Brazilian stock market, represented by the MSCI Brazil index. In contrast, the global stock market portfolio is characterized by the profitability index of the global stock market, represented by the MSCI ACWorld stock index. These two indices are calculated by the financial services company Morgan Stanley Capital Internacional (MSCI). They will be discussed below in the section dealing with the data used in this work. The market model can be described as follows:

$R_{t}=\alpha+\beta R_{M t}+e_{t}$

where: $R_{t}=$ return of the MSCI Brazil index in period $\mathrm{t}$; and $\mathrm{R}_{M t}=$ return on the ACWorld index or global stock market portfolio in period t. From the market model, the conditional average and conditional variance of the returns on financial assets that can be determined as follows

mean: $E\left(R_{t} \mid R_{M t}\right)=\alpha+\beta R_{M t}$

variance: $V\left(R_{t} \mid R_{M t}\right)=\beta^{2} V\left(R_{M t}\right)+V\left(e_{t}\right)$

The total risk, measured by the conditional variance, can be divided into market risk and idiosyncratic risk according to the expression [3] above. The first installment represents a market risk, while the second installment represents an idiosyncratic risk. The beta coefficient is the main systematic risk indicator, while the market model stochastic terms variance determines the idiosyncratic risk. The estimation of the beta coefficient takes place through econometric methods applied to linear regression models, such as in the works by Scholes and Williams (1977) using a univariate model and by (A. A. Salles, 2006) using a multivariate model. The estimation of idiosyncratic risk can be done through stochastic volatility models such as the ARCH family models, particularly the GARCH suggested by Engle (1982) and Bollerslev (1986), respectively. The GARCH model, proposed by Bollerslev (1986), seeks to assimilate a standard behavior in the return series of financial assets. High values also follow large values in the following periods, not necessarily in the same direction, following a predictable process. Once alpha and beta parameters are more significant than zero, a GARCH model (p, q) can be described in its general form by the expression:

$\sigma_{t}^{2}=\alpha_{0}+\sum_{j=1}^{q} \alpha e_{t-j}^{2}+\sum_{j=1}^{p} \beta \sigma_{t-j}^{2}$

Hence, in addition to the ARCH and GARCH models, other well-known ARCH family models such as IGARCH, EGARCH, and TGARCH were tested. The model selection criterion suggested by Akaike, the AIC, which can be seen in Gujarati and Porter (2011)or Wooldridge (2012), was used to select the ARCH family model. The model selected and used in this work to estimate the idiosyncratic risk was a heteroscedastic regression model, where the stochastic terms follow a GARCH $(1,1)$ model, that can be described as follows:

$R_{t}=\alpha+\beta R_{M t}+e_{t}, e_{t} \sim$ Student $\left(0 ; \sigma_{t}^{2} ; v\right)$

$\sigma_{t}^{2}=\alpha_{0}+\alpha e_{t-1}^{2}+\beta \sigma_{t-1}^{2}$

The estimation of the market model for the Brazilian market described above in [5] used the sample of returns from profitability indexes of the MSCI Brazil and MSCI ACWorld markets. Therefore, the idiosyncratic risk time series were obtained from this GARCH $(1,1)$ model results.

To achieve the purpose of this work, multivariate stochastic models were utilized in particular bivariate models developed from the autoregressive vector models. Presented in the econometric literature by Sims (1980), these models do not distinguish endogenous and exogenous variables and allow for the study of the relationship between two or more stochastic variables, innovations, or shocks that one variable can transmit to another or other variables and verify the short and longrun relationship between the variables involved. Also, one can verify the hypothesis of Granger causality among the variables involved (see Granger (1969) and Sims (1972)). Considering two variables of interest for this research, the idiosyncratic risk, from now on IDR, and the EMBI+ the VAR model can be described in its simplest form by the following system of equations:

$Y_{t}=\beta_{1}+\beta_{2} Y_{t-1}+\beta_{3} Z_{t-1}+\varepsilon_{1 t}$ 
$Z_{t}=\beta_{4}+\beta_{5} Z_{t-1}+\beta_{6} Y_{t-1}+\varepsilon_{2 t}$

where the variables $Y_{t}$ and $Z_{t}$ are stationary, and $\varepsilon_{1 t}$ and $\varepsilon_{2 t}$ have an expected value equal to zero and are orthogonal. In this work, the variable $Y_{t}$ represents the variable IDR while the variable $Z_{t}$ the EMBI+ Brazil. If the cointegrating hypothesis between these variable's time series is not rejected, the VAR model must be modified to VEC model or VECM. The VECM takes into consideration the cointegration between these variables through the error correction mechanism (ECM), a linear combination between $Y_{t}$ and $Z_{t}$ (see Salles and Almeida (2017)). This VECM model can be described in its simplest form as follow:

$Y_{t}=\beta_{1}+\beta_{2} E C M+\beta_{3} Y_{t-1}+\beta_{4} Z_{t-1}+\varepsilon_{1 t}$

$Z_{t}=\beta_{5}+\beta_{6} E C M+\beta_{7} Z_{t-1}+\beta_{8} Y_{t-1}+\varepsilon_{2 t}$

\section{Results and Discussion}

The primary data that formed the sample used in this work were collected on the Ipeadata website, www.ipeadata.gov.br, for EMBI +, and on the Investing.com website for the profitability indices of the Brazilian stock Market -- the MSCI Brazil Index -- and profitability of the global stock market -- MSCI All-Country World Equity Index -- or simply MSCI ACWorld Index, calculated by the financial services company Morgan Stanley Capital International (MSCI). These collected data were transformed into close weekly data, that is, the latter trading day of the week covering the period from June 7, 2009, to March 22, 2020, generating 564 weekly quotations of the equity market indices collected.

The IDR time series was obtained by estimating the market model given by the expressions shown in [5] with the stochastic terms adjusted to a Student $t$ distribution with approximately 7 degrees of freedom. The mean, variance, and performance metrics of the estimates are shown respectively in Table 1.

Table 1. The Brazilian IDR Model Estimation Results

\begin{tabular}{lcll}
\hline Mean Equation & MSCI Brt $=-0.0031+1.3442$ ACWORD & \\
se $(0.0011)$ & $(0.0451)$
\end{tabular}

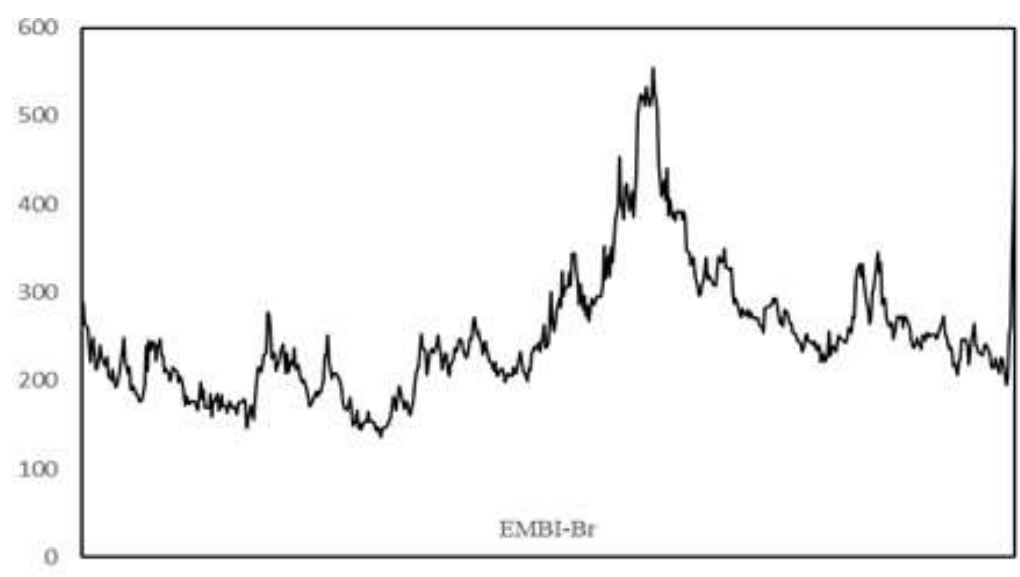

Figure 1. The Brazilian Country Risk 


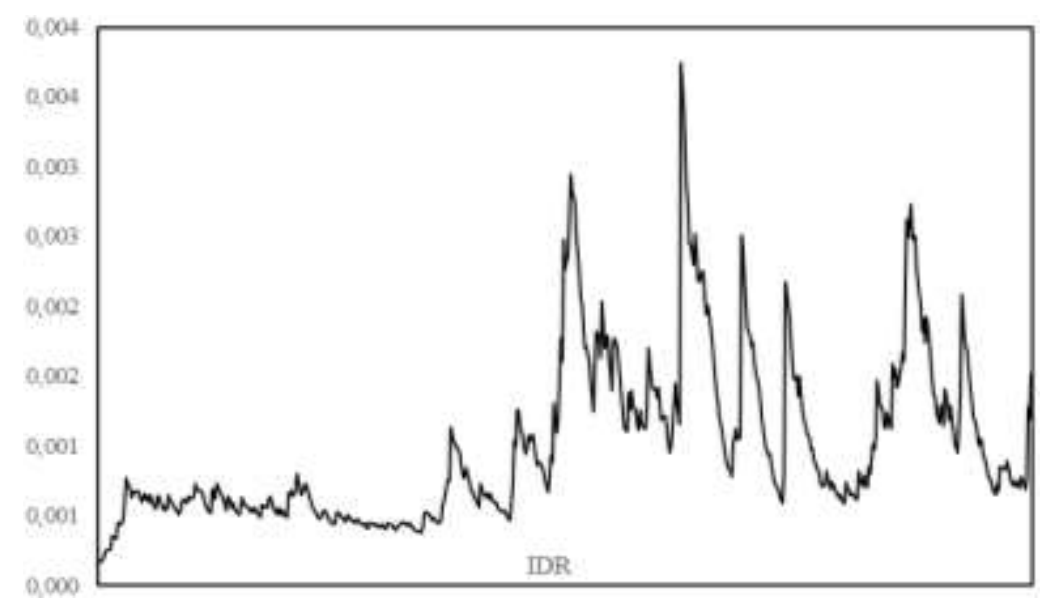

Figure 2. The Brazilian Idiosyncratic Risk

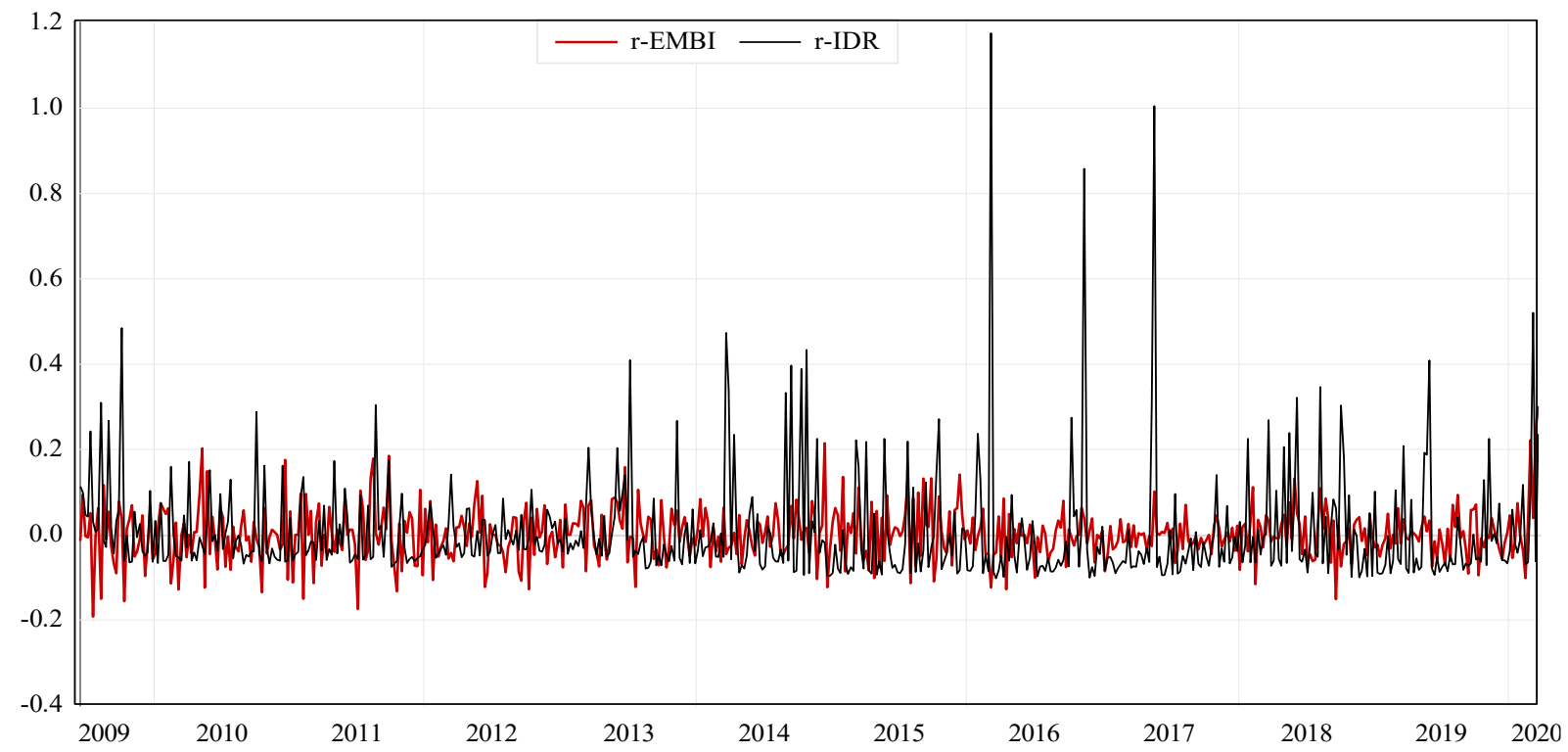

Figure 3. The Brazilian Indicator of the Country Risk and Idiosyncratic Risk Variations

From the EMBI+ and IDR time series estimates obtained, the VECM model for the elaboration of this work was implemented. The behavior and evolution of these time series during the studied period can be observed in the plots presented in Figures 1 and 2. Figure 3 presented the plots of the evolution of the variation of these indicators in the period, showing their interactions has some limitations.

Table 2. Statistical Summary of Time Series

\begin{tabular}{lcccc}
\hline Statistics & $\begin{array}{c}\text { EMBI+ } \\
\text { Quotes }\end{array}$ & $\begin{array}{c}\text { IDR } \\
\text { Estimates }\end{array}$ & $\begin{array}{c}\text { EMBI+ } \\
\text { Variations }\end{array}$ & $\begin{array}{c}\text { IDR } \\
\text { Variations }\end{array}$ \\
\hline Mean & 251.9751 & 0.0010 & 0.0009 & 0.0042 \\
Median & 239.0000 & 0.0008 & 0.0000 & -0.0379 \\
Maximum & 554.0000 & 0.0037 & 0.3018 & 1.1756 \\
Minimum & 137.0000 & 0.0002 & -0.1923 & -0.1022 \\
Std Deviation & 72.5232 & 0.0006 & 0.0616 & 0.1265 \\
\hline Skewness & 1.4714 & 1.4073 & 0.4388 & 3.9026 \\
Kurtosis & 5.9014 & 4.8734 & 4.8639 & 27.1381 \\
Jarque-Bera test & 400.6215 & 268.1563 & 99.5605 & 15096.96 \\
(p value) & $(0.0000)$ & $(0.0000)$ & $(0.0000)$ & $(0.0000)$ \\
\hline ADF test & -2.7425 & -4.4010 & -16.0360 & -23.2816 \\
(p value) & $(0.2198)$ & $(0.0023)$ & $(0.0000)$ & $(0.0000)$ \\
\hline
\end{tabular}


correction mechanisms, is the appropriate model to obtain necessary inferences that concern these variables' interaction.

This way, the VECM model estimation proceeded. The two equations of the VECM model estimates are shown in Table 3 in which the parameter estimated with standard errors, $t$ statistics, and $\mathrm{p}$ values were presented. These results allow inferring that all parameter estimates are statistically significant and the model was estimated satisfactorily, which is confirmed with the Residual Covariance Determinant (DRC) close to zero and an AIC close to -3.79. The other model adjustment metrics and each of the autoregressive vector models with error correction can also be seen in Table 3.

From these results, tests of significance of the error correction mechanisms coefficients $\beta_{1}$ and $\beta_{6}$ were implemented and are shown in Table 2 , which, with the non-rejection of the statistical significance hypothesis, indicate the existence of a long-run relationship between rEMBI + and rIDR. The Wald test the null hypothesis of these coefficients was not accepted as equal to zero, which confirms the long-run relationship between the variables rEMBI + and rIDR.

For the short-run relationship, the significance of the coefficients indicates that this hypothesis can not be rejected. Another important inference concerns the Granger causality test. The Granger causality test hypothesis points out the no rejection of bidirectional causality between the two indicators which is confirmed by the Wald test of exogeneity. There fore, it can be inferred that there is interaction in the short and long run between the two variables.
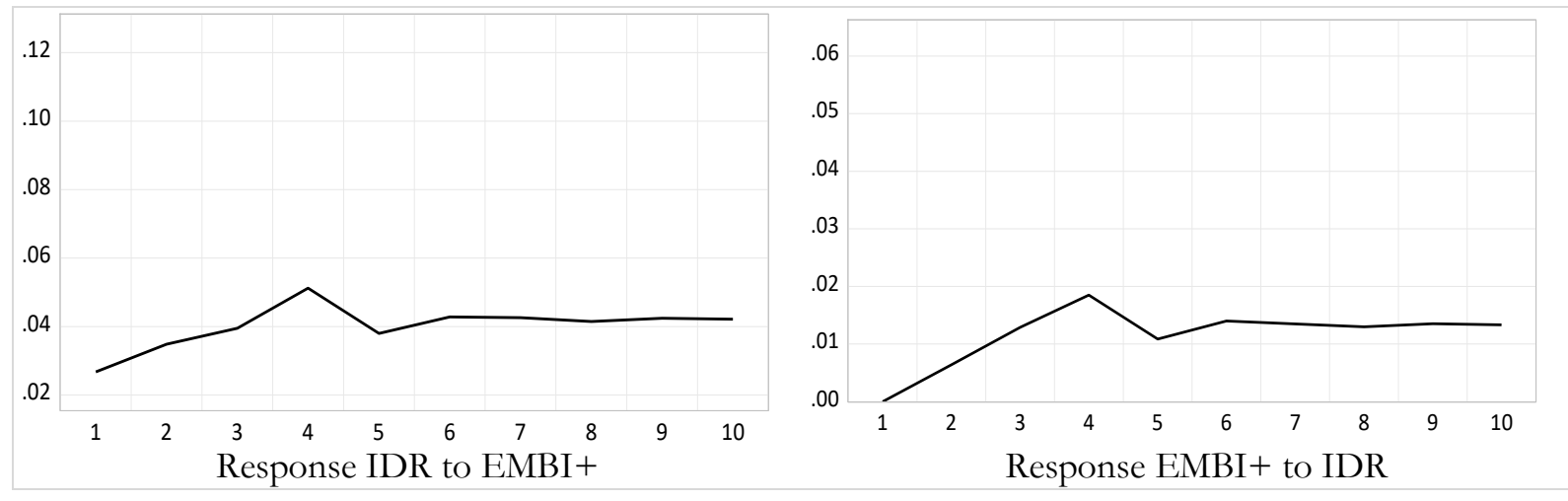

Figure 4. Impulse Response Function
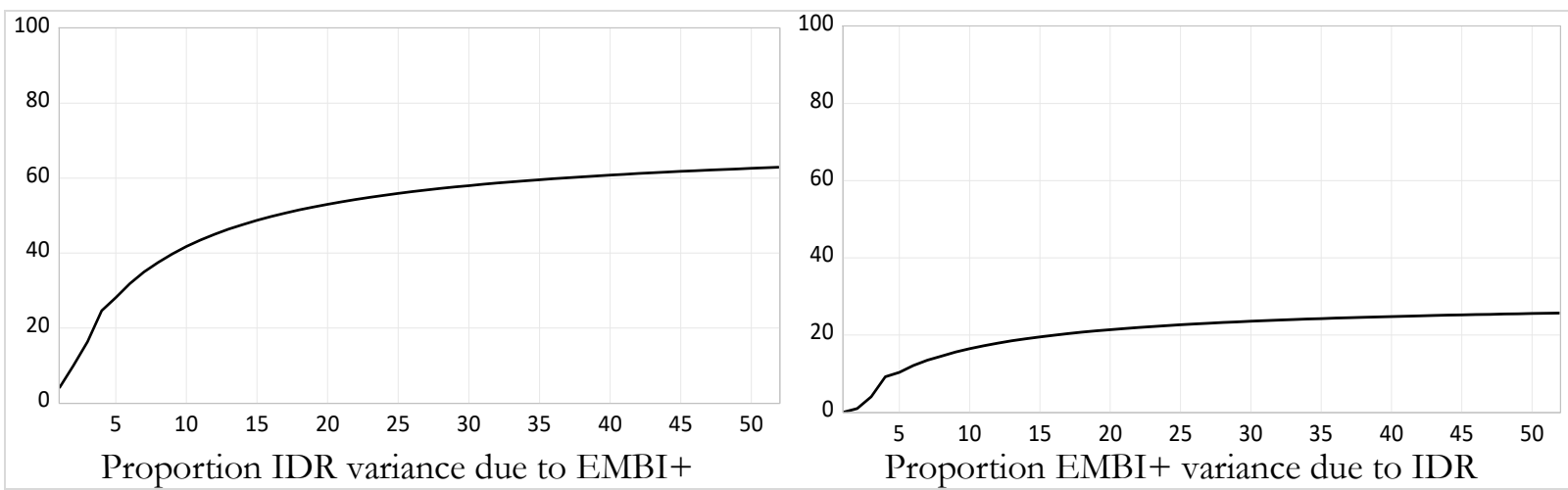

Figure 5. Variance Decomposition

Regarding the impulse response function between the variables, the plots indicated in Figure 4 allow observing how and when the response happens or lag one variable shocks on the other. That is, the responses of the variation of the country risk in the variation of the idiosyncratic risk and the variation of the idiosyncratic risk in the variation of the country risk. Concerning the variance decomposition of a variable into the other, the plot is presented in Figure 5. It can be observed that the most extensive participation in the variable variances occurs with a lag close to 10 periods or weeks, both for EMBI+ and for IDR. As Brooks (2002) observes, variance 
decompositions "give the proportion of movements in the dependent variables that are due to their own shocks, versus to the other variables." Additionally, Table 4 allows observing in each period listed the proportion of the explanation of the variation or of the shocks of the idiosyncratic risk due to the EMBI+ shocks and the proportion of the variation of the EMBI + due to the shocks of the variation of the idiosyncratic risk. Table 4 presents the decomposition of variance for IDR and $\mathrm{EMBI}+$ time series.

The first four columns of the table show the variance decomposition of the idiosyncratic risk, namely, the first column shows the period analyzed. The second column shows the standard error of the forecast of the IDR, the third column the proportion of the variance due to shocks the IDR variable itself. In contrast, the fourth column exhibits the proportion of the variation in the explained IDR or due to EMBI+ shocks. This description could be repeated for the last four columns of Table 4 that refer to the variance decomposition of the EMBI+. It can be observed that after four weeks, approximately $25 \%$ of the variation of the EMBI+ explains the variation of the IDR while $9 \%$ IDR explains the variation of the EMBI+. After 52 weeks, approximately $62 \%$ of the variation of the EMBI+ explains the variation of the IDR, while approximately $26 \%$ IDR explains the variation in EMBI+.

Table 4. Variance Decomposition -- IDR and EMBI+

\begin{tabular}{cccccccc}
\hline Period & Std Error & IDR EMBI+ & IDR & Period* & Std Error* & EMBI+*EMBI+* & IDR* \\
\hline 1 & 0.1339 & 3.9973 & 96.0027 & 1 & 0.0662 & 100.0000 & 0.0000 \\
2 & 0.1392 & 9.9604 & 90.0396 & 2 & 0.0668 & 99.0867 & 0.9133 \\
3 & 0.1462 & 16.3381 & 83.6619 & 3 & 0.0720 & 96.0088 & 3.9912 \\
4 & 0.1576 & 24.6203 & 75.3797 & 4 & 0.7740 & 90.8367 & 9.1633 \\
8 & 0.1857 & 37.4914 & 62.5086 & 8 & 0.0913 & 85.4492 & 14.5508 \\
12 & 0.2110 & 45.0191 & 54.9809 & 12 & 0.1039 & 82.1179 & 17.8821 \\
24 & 0.2730 & 55.4279 & 44.5721 & 24 & 0.1346 & 77.5617 & 22.4383 \\
36 & 0.3234 & 59.8583 & 40.1417 & 36 & 0.1596 & 75.6295 & 24.3706 \\
52 & 0.3803 & 62.9030 & 37.0971 & 52 & 0.1877 & 74.3042 & 25.6958 \\
\hline
\end{tabular}

*Variance Decomposition of EMBI+

The study results cannot be generalized because different developing countries and/or country groups have different economic features. Furthermore, the model was specified to test the links between only two variables. Therefore, introducing more growth factors may present different results.

\section{Conclusion}

This work aimed to estimate a proxy for a time series of the Brazilian economy idiosyncratic risk and compare the time series results obtained from the country risk measure EMBI+, which is most widespread among resource managers in the international market.

The results show similarities or associations between the two indicators with interactions in the short and long run. This way, the IDR proves to be a relevant indicator regarding the risk of economic activities implemented within the scope of the Brazilian economy and can be useful in evaluating investments in related projects. This indicator provides resource managers an alternative for obtaining estimates of the expected return required by economic agents in financing and investing in productive and infrastructure projects necessary for developing the Brazilian economy that provides greater employability and acceptable social welfare. Thus the objectives of this work were achieved.

Future research works on this theme, it is important to verify what happens in other economies, which refer to the idiosyncratic risk behavior and the associations and interactions of country risk indicator and idiosyncratic risk and their behavior in economies in general. Furthermore, it is meant to highlight the use of other methodological approaches. 


\section{References}

Alfaro, R., Medel, C., \& Moreno, C. (2017). An analysis of the impact of external financial risks on the sovereign risk premium of Latin American economies. Revista de Analisis Economico - Economic Analysis Review, 32(2), 131-153.

Anderson, R. M., Heesterbeek, H., Klinkenberg, D., \& Hollingsworth, T. D. (2020). How will country-based mitigation measures influence the course of the COVID-19 epidemic? Lancet (London, England), 395(10228), 931-934. https://doi.org/10.1016/S01406736(20)30567-5

Angelidis, T., \& Tessaromatis, N. (2008). Idiosyncratic volatility and equity returns: UK evidence. International Review of Financial Analysis, 17(3), 539-556. https://doi.org/10.1016/j.irfa.2006.10.006

Atkenson, A. (2020). What will be the economic impact of Covid-19 in the US? (NBER Working Paper Series No. 26867). Retrieved from http://www.nber.org/papers/w26867

Barro, R., Ursua, J. F., \& Weng, J. (2020). The coronavirus and the great influenza epidemic: Lessons from the "Spanish Flu" for coronavirus's potential effects on mortality and economic activity (CESifo Working Paper No. 8166). Munich.

Blitz, D., Hanauer, M. X., \& Vidojevic, M. (2020). The idiosyncratic momentum anomaly. International Review of Economics Eamp; Finance, 69(C), 932-957. https://doi.org/10.1016/j.iref.2020.05.008

Bollerslev, T. (1986). Generalized autoregressive conditional heteroskedasticity. Journal of Econometrics, 31(3), 307-327. https://doi.org/10.1016/0304-4076(86)90063-1

Brooks, C. (2002). Introductory econometrics for finance. Cambridge: Cambridge University Press.

Campbell, J., Hilscher, J., \& Szilagyi, J. (2008). In search of distress risk. Journal of Finance, 63(6), 2899-2939.

Chang, R. P., Ko, K.-C., Nakano, S., \& Ghon Rhee, S. (2018). Residual momentum in Japan. Journal of Empirical Finance, 45, 283-299. https://doi.org/10.1016/j.jempfin.2017.11.005

Cristo, M. L., \& Gómez-Puig, M. (2014). Dollarization and the relationship between EMBI and fundamentals in Latin American countries (Working Paper No. 2014/02). Barcelona.

Enders, W. (2010). Applied econometric time series (3rd ed.). New York: John Wiley \& Sons.

Engle, R. F. (1982). Autoregressive conditional heteroscedasticity with estimates of the variance of United Kingdom inflation. Econometrica, 50(4), 987-1007. https://doi.org/10.2307/1912773

Fama, E. F., \& French, K. R. (1993). Common risk factors in the returns on stocks and bonds. Journal of Financial Economics, 33(1), 3-56. https://doi.org/10.1016/0304-405X(93)90023-5

Fu, F. (2009). Idiosyncratic risk and the cross-section of expected stock returns. Journal of Financial Economics, 91(1), 24-37. https://doi.org/10.1016/j.jfineco.2008.02.003

Gourinchas, P. O. (2020). Flattening the pandemic and recession curves. Berkeley. Retrieved from https://clausen.berkeley.edu/wp-content/uploads/2020/03/COVID_2b.pdf

Granger, C. (1969). Investigating causal relations by econometric models and cross-spectral methods. Econometrica, 37(3), 424-438. https://doi.org/10.2307/1912791

Gujarati, D., \& Porter, D. (2011). Basic Econometric (4th ed.). New York: The McGraw-Hill Companies.

Kalra, S. (2008). Global volatility and forex returns in East Asia (IMF Working Paper No. WP/08/208). Retrieved from https://www.imf.org/external/pubs/ft/wp/2008/wp08208.pdf 
Kocsis, Z. (2013). Global, regional and country-specific components of financial market: An extraction method and applications (MNB Working Paper No. 3). Retrieved from https://www.mnb.hu/letoltes/wp-2013-03-final-1.pdf

Markowitz, H. (1952). Portfolio Selection. The Journal of Finance, 7(1), 77-91. https://doi.org/10.1111/j.1540-6261.1952.tb01525.x

Mckibbin, W., \& Fernando, R. (2020). The global macroeconomic impacts of Covid-19: Seven scenarios. Washington, DC. Retrieved from https://www.brookings.edu/wpcontent/uploads/2020/03/20200302_COVID19.pdf

Naidenova, I., Parshakov, P., \& Shakina, E. (2020). Idiosyncratic and systematic shocks of COVID-19 pandemic on financial markets (SSRN Journal). Rochester. https://doi.org/10.2139/ssrn.3574774

Rosenberg, B., \& McKibben, W. (1973). The prediction of systematic and specific risk in common stocks. The Journal of Financial and Quantitative Analysis, 8(2), 317-333. https://doi.org/10.2307/2330027

Salles, A. A. (2006). Evaluation and seasonality of the market risk in Latin América: A Bayesian approach. Anales del XIII Congreso Latino-Iberoamericano de Investigación Operativa, Montevideo, Asociación Latino-Iberoamericano de Investigación Operativa (ALIO).

Salles, A., \& Almeida, P. (2017). The crude oil price influence on the Brazilian industrial production. Open Journal of Business and Management, 5(2), 401-414. https://doi.org/10.4236/ojbm.2017.52034

Scholes, M., \& Williams, J. (1977). Estimating betas from nonsynchronous data. Journal of Financial Economics, 5(3), 309-327. https://doi.org/10.1016/0304-405X(77)90041-1

Sharpe, W. (1963). A simplified model of portfolio analysis. Management Science, 9(2), 277-293. https://doi.org/10.1287/mnsc.9.2.277

Shi, H.-L., \& Zhou, W.-X. (2019). Weekly idiosyncratic risk metrics and idiosyncratic momentum: Evidence from the Chinese stock market.

Sims, C. (1972). Money, income, and causality. American Economic Review, 62(4), 540-552.

Sims, C. (1980). Macroeconomics and Reality. Econometrica, 48(1), 1-48. https://doi.org/10.2307/1912017

Wooldridge, J. M. (2012). Introductory econometrics: A modern approach (5th ed.). Chicago Wooldridge: South-Western Pub, Mason. 